\title{
Heterogeneously entrapped, vapor-rich melt inclusions record pre eruptive magmatic volatile contents
}

DOI:

10.1007/s00410-017-1343-3

\section{Document Version}

Accepted author manuscript

Link to publication record in Manchester Research Explorer

\section{Citation for published version (APA):}

Steele-Maclnnis, M., Esposito, R., Moore, L. R., \& Hartley, M. E. (2017). Heterogeneously entrapped, vapor-rich melt inclusions record pre eruptive magmatic volatile contents. Contributions to Mineralogy and Petrology, 172. https://doi.org/10.1007/s00410-017-1343-3

\section{Published in:}

Contributions to Mineralogy and Petrology

\section{Citing this paper}

Please note that where the full-text provided on Manchester Research Explorer is the Author Accepted Manuscript or Proof version this may differ from the final Published version. If citing, it is advised that you check and use the publisher's definitive version.

\section{General rights}

Copyright and moral rights for the publications made accessible in the Research Explorer are retained by the authors and/or other copyright owners and it is a condition of accessing publications that users recognise and abide by the legal requirements associated with these rights.

\section{Takedown policy}

If you believe that this document breaches copyright please refer to the University of Manchester's Takedown Procedures [http://man.ac.uk/04Y6Bo] or contact uml.scholarlycommunications@manchester.ac.uk providing relevant details, so we can investigate your claim.

\section{OPEN ACCESS}


Click here to view linked References

1 MI: heterogeneously entrapped bubbles

v.021017

3

1 Heterogeneously entrapped, vapor-rich melt inclusions record preeruptive magmatic volatile contents

3

4 5

18 *Corresponding author. Email: steelemacinnis@email.arizona.edu

Tel.: 520-621-1385

Fax: 520-621-2672 Los Angeles CA 90095 USA

${ }^{3)}$ Department of Geosciences, Virginia Tech, Blacksburg VA 24061 USA UK

${ }^{2)}$ Department of Earth, Planetary and Space Sciences, University of California, Los Angeles,

${ }^{4)}$ School of Earth and Environmental Sciences, University of Manchester, Manchester M13 9PL 
23 Silicate melt inclusions (MI) commonly provide the best record of pre-eruptive $\mathrm{H}_{2} \mathrm{O}$ and $\mathrm{CO}_{2}$

24 contents of subvolcanic melts, but the concentrations of $\mathrm{CO}_{2}$ and $\mathrm{H}_{2} \mathrm{O}$ in the melt (glass) phase

25 within MI can be modified by partitioning into a vapor bubble after trapping. Melt inclusions

26 may also enclose vapor bubbles together with the melt (i.e., heterogeneous entrapment), affecting

27 the bulk volatile composition of the MI, and its post-entrapment evolution. Here, we use

28 numerical modeling to examine the systematics of post-entrapment volatile evolution within MI

29 containing various proportions of trapped vapor from zero to 95 volume percent. Modeling

30 indicates that inclusions that trap only a vapor-saturated melt exhibit significant decrease in $\mathrm{CO}_{2}$

31 and moderate increase in $\mathrm{H}_{2} \mathrm{O}$ concentrations in the melt upon nucleation and growth of a vapor

32 bubble. In contrast, inclusions that trap melt plus vapor exhibit subdued $\mathrm{CO}_{2}$ depletion at

33 equivalent conditions. In the extreme case of inclusions that trap mostly the vapor phase (i.e.,

$34 \mathrm{CO}_{2}-\mathrm{H}_{2} \mathrm{O}$ fluid inclusions containing trapped melt), degassing of $\mathrm{CO}_{2}$ from the melt is negligible.

35 In the latter scenario, the large fraction of vapor enclosed in the MI during trapping essentially

36 serves as a buffer, preventing post-entrapment modification of volatile concentrations in the

37 melt. Hence, the glass phase within such heterogeneously entrapped, vapor-rich MI records the

38 volatile concentrations of the melt at the time of trapping. These numerical modeling results

39 suggest that heterogeneously entrapped MI containing large vapor bubbles represent amenable

40 samples for constraining pre-eruptive volatile concentrations of subvolcanic melts.

41 Keywords: silicate melt; melt inclusions; fluid inclusions; vapor bubbles; $\mathrm{H}_{2} \mathrm{O} ; \mathrm{CO}_{2}$; degassing 
44 Silicate melt inclusions (MI) are aliquots of melt trapped within crystals during crystal growth or

45 fracture healing (Lowenstern 1995; Lowenstern 2003; Bodnar and Student 2006; Cannatelli et al. 46 2016), although Lowenstern (1995) noted that trapping secondary MI in volcanic phenocrysts

47 may be unlikely owing to the viscosity of silicate melts. As such, MI represent samples of the 48 melt during various stages of fractionation in an evolving magmatic system, providing a record 49 of igneous processes which may be otherwise inaccessible. The evolution of dissolved volatiles 50 (e.g., $\mathrm{CO}_{2}, \mathrm{H}_{2} \mathrm{O}, \mathrm{Cl}, \mathrm{S}$, etc.) in the melt is one such process. Crystal-hosted melt inclusions in 51 volcanic rocks can be analyzed to constrain the concentrations of volatile components dissolved 52 in the melt prior to volcanic eruption and/or degassing. If the melt reached saturation with a 53 magmatic fluid or vapor phase prior to eruption, then measured volatile concentrations can be 54 interpreted according to solubility models (e.g., Holloway and Blank 1994; Newman and 55 Lowenstern 2002; Papale et al. 2006; Shishkina et al., 2014) to constrain depths of magma 56 emplacement as well as progressive degassing of an initially $\mathrm{CO}_{2}$-enriched melt during ascent 57 (Lowenstern 1994; Métrich and Wallace 2008).

58 Apparently coeval melt inclusions commonly record wide ranges of $\mathrm{CO}_{2}$ concentrations 59 in the glass phase (Esposito et al. 2014). Variation in volatile concentrations of MI glasses can be 60 induced independently of magma degassing, as a result of several potential post-entrapment 61 processes. Firstly, volatile concentrations in the melt in an inclusion can be modified by diffusive 62 re-equilibration with the exterior carrier melt (Qin et al. 1992; Danyushevsky et al. 2000;

63 Portnyagin et al. 2008; Mironov and Portnyagin 2011; Gaetani et al. 2012; Bucholz et al. 2013; 64 Mironov et al. 2015; Hartley et al. 2015). This process can occur on timescales of days to hours 65 in some cases. Secondly, volatile components within MI can be partitioned between the melt and 
66 a vapor phase (bubble) subsequent to trapping (Anderson and Brown 1993; Steele-MacInnis et 67 al. 2011; Hartley et al. 2014; Moore et al. 2015; Wallace et al. 2015; Tuohy et al. 2016; Aster et 68 al. 2016). A vapor phase within an initially homogeneous melt inclusion may nucleate and grow 69 after trapping as a result of differential thermal contraction of melt versus the host crystal 70 (Lowenstern 2003; Moore et al. 2015), by post-entrapment crystallization (PEC; Steele-MacInnis 71 et al. 2011) of the host mineral on the inclusion walls, or a combination of these processes. In all 72 three scenarios, nucleation and growth of the vapor bubble results in strong depletion of $\mathrm{CO}_{2}$ 73 from the melt phase with concomitant minor variation in the $\mathrm{H}_{2} \mathrm{O}$ concentration. The divergent 74 trends in $\mathrm{CO}_{2}$ versus $\mathrm{H}_{2} \mathrm{O}$ concentration in the melt are a consequence of the extremely different $75 \mathrm{CO}_{2} / \mathrm{H}_{2} \mathrm{O}$ ratios in the melt versus the exsolving fluid phase: In general, the $\mathrm{CO}_{2} / \mathrm{H}_{2} \mathrm{O}$ ratio in the 76 exsolving vapor is significantly greater than that in the coexisting melt (i.e., $\mathrm{CO}_{2}$-rich vapor 77 exsolved from a melt which is generally more enriched in $\mathrm{H}_{2} \mathrm{O}$ ), and as such the exsolution of the 78 vapor phase drives the $\mathrm{CO}_{2} / \mathrm{H}_{2} \mathrm{O}$ ratio of the melt to lower values. Thus, several studies have 79 used Raman spectroscopy to determine the amount of $\mathrm{CO}_{2}$ exsolved into the bubble to constrain 80 the bulk $\mathrm{CO}_{2}$ content of the inclusion (e.g., Esposito et al. 2011; Moore et al. 2015; Hartley et al. 81 2014; Tuohy et al. 2016). The $\mathrm{H}_{2} \mathrm{O}$ in the vapor bubble has not generally been detected during 82 Raman spectroscopic analysis of MI vapor bubbles, but has recently been detected as a rim of $83 \mathrm{H}_{2} \mathrm{O}$-rich liquid at the glass/bubble interface in re-heated MI (Esposito et al. 2016). Like the case 84 for $\mathrm{CO}_{2}$, Esposito et al. (2016) suggested that depending on the initial conditions, most of the $85 \mathrm{H}_{2} \mathrm{O}$ and of the $\mathrm{S}$ of the originally trapped melt may be stored in the bubble.

86 Heterogeneous entrapment represents an alternative origin for the vapor bubbles in some 87 MI. In this scenario, the host phenocryst encloses a multi-phase assemblage of vapor-saturated 88 melt plus vapor. Evidence for heterogeneous entrapment of melt plus magmatic fluid has been 
89 reported in several studies. For example, Harris et al. (2003), Zajacz et al. (2008) and Stefanova 90 et al. (2014) described MI from high-temperature porphyry veins, containing globules of high-

91 density, high-salinity brine. In these studies, the brine globules are interpreted as trapped

92 hydrothermal fluid, which presumably exsolved from the silicate melt prior to trapping of the 93 melt inclusions. Bodnar and Student (2006) noted that in the case of heterogeneous entrapment, 94 the volume fraction of vapor would likely be variable for groups of coevally entrapped MI (or 95 melt inclusion assemblages; MIA). Moore et al. (2015) developed a numerical model to estimate 96 the maximum volume fraction of vapor expected as a result of differential thermal contraction 97 for MI hosted in various minerals, and concluded that in general, vapor bubbles of up to a few 98 percent of the MI volume are consistent with bubble nucleation and growth by this mechanism. 99 As such, vapor bubbles exceeding a few volume percent of the MI may represent trapped vapor 100 (Fig. 1). Aster et al. (2016) similarly used a numerical model to estimate the maximum volume 101 fraction of vapor expected purely from cooling, PEC and quenching of initially homogeneous 102 trapped melt, and used this information to infer which MI appeared to have trapped some portion 103 of vapor. Hartley et al. (2014) and Moore et al. (2015) reported melt inclusions containing exceptionally large vapor bubbles up to several tens of volume percent, suggesting that these MI 
112 anomalously large vapor bubbles (Bucholz et al., 2013; Aster et al. 2016), which is not

113 considered in the present study. In addition, decrepitation and/or leakage of MI may also

114 contribute to forming anomalously large bubbles, as discussed below.

115 The occurrence of MI containing a heterogeneously trapped vapor phase raises questions

116 as to the systematics of melt-vapor partitioning within inclusions that trapped both melt and

117 vapor. Conceptually, coeval melt inclusions and fluid inclusions are expected to follow different

118 temperature-pressure trajectories subsequent to trapping (Fig. 2). The pressure-temperature

119 trajectory followed by a vapor-saturated silicate melt inclusion is a function of compressibility

120 and expansivity of melt and vapor, the vapor solubility relations, and the evolution of PEC

121 (Student and Bodnar 1996; Steele-MacInnis et al. 2011; Schiavi et al. 2016). In contrast, the

122 temperature-pressure trajectory for $\mathrm{CO}_{2}-\mathrm{H}_{2} \mathrm{O}$ fluid inclusions is constrained by the isochore

123 (pressure-temperature locus of constant density) of the $\mathrm{CO}_{2}-\mathrm{H}_{2} \mathrm{O}$ fluid phase (Sterner and

124 Bodnar, 1991; Diamond, 2003) according to the composition and bulk density of the fluid. For

125 example, Mironov and Portnyagin (2011) estimated the trapping temperature and pressure

126 conditions of coeval melt and fluid inclusions hosted in olivine by intersecting the temperature

127 estimated from MI with the isochores of the coeval $\mathrm{CO}_{2}-\mathrm{H}_{2} \mathrm{O}$ fluid inclusions. As such, the

128 temperature-pressure trajectory followed by heterogeneously entrapped, vapor-rich MI is

129 expected to vary between these two endmembers according to the proportion of trapped vapor

130 (Fig. 2). Moreover, the temperature-pressure trajectory of the MI is expected to tend towards the 131 coeval fluid-inclusion isochore at high proportions of trapped vapor. Steele-MacInnis et al.

132 (2011) reported that evolution of $\mathrm{CO}_{2}$ and $\mathrm{H}_{2} \mathrm{O}$ concentrations in the melt (glass) within $\mathrm{MI}$ is 133 correlated to the pressure-temperature trajectory followed by the MI after trapping. Hence, we expect that the volatile systematics of heterogeneously entrapped MI will also vary according to 
135 the proportion of trapped vapor. Stated differently, the partitioning of volatile components

136 between melt and vapor is sensitive to the relative proportions of phases trapped. Thus,

137 interpreting volatile contents of MI glass, bubble, and bulk inclusion can be complicated by

138 heterogeneous entrapment.

139 In this study, we build upon the earlier thermodynamic modeling of Steele-MacInnis et 140 al. (2011) to characterize volatile evolution of MI melt (glass) and vapor during post-entrapment 141 crystallization of heterogeneously entrapped MI. Steele-MacInnis et al. (2011) focused on MI

142 that trapped only vapor-saturated melt (without trapped vapor), and reported contrasting behavior 143 of $\mathrm{CO}_{2}$-rich versus $\mathrm{H}_{2} \mathrm{O}$-rich melts and intermediate $\mathrm{CO}_{2}-\mathrm{H}_{2} \mathrm{O}$-saturated melts. Here, we extend 144 these results to heterogeneously entrapped inclusions, including end-member scenarios of 145 homogeneously entrapped melt or vapor, and several intermediate scenarios with various relative 146 proportions of trapped melt and vapor. In the present contribution, we do not include the effects 147 of diffusive re-equilibration, nor the effects of bubble expansion during syn-eruptive cooling and 148 quenching, although we recognize that these effects may be significant for many natural MI and 149 that future studies incorporating them will be necessary. As such, the present contribution 150 represents one endmember of the various complexities that can manifest in MI volatile 151 systematics. The results of this analysis indicate that for inclusions that trap a large proportion of 152 vapor, the $\mathrm{H}_{2} \mathrm{O}$ and $\mathrm{CO}_{2}$ concentrations in the melt (glass) phase within the inclusion are 153 relatively insensitive to post-entrapment crystallization. These results thus suggest that 154 heterogeneously entrapped MI may represent amenable samples for characterizing pre-eruptive 155 dissolved volatile contents of melts.

\section{METHODS}


The methods used here were mostly described in detail by Steele-MacInnis et al. (2011), so here we provide only an abridged overview (see Steele-MacInnis et al., 2011 for additional details). We modeled the effects of volatile exsolution during post-entrapment crystallization of an albitic ( $\left.\mathrm{NaAlSi}_{3} \mathrm{O}_{8}\right)$ melt trapped in albite using constant volume (isochoric), constant composition (closed) boundary conditions. The albitic model was used primarily because this 163 system represents a relatively simple endmember, and because the parameterization is very well 164 constrained. In addition, we extended this model to basaltic melts trapped in olivine, because the latter system is one of the most widely studied in terms of natural MI and information relative to bubble and MI are available from the literature (e.g., Hartley et al. 2014; Moore et al., 2015). The methods used in this modeling are described below.

For the albitic melt, solubilities of $\mathrm{H}_{2} \mathrm{O}$ and $\mathrm{CO}_{2}$ in the melt were calculated according to the models described by Holloway and Blank (1994). Volumetric properties of albitic melt and albite were calculated using the model of Burnham and Davis $(1971 ; 1974)$. To initiate the model, the composition of vapor-saturated melt in equilibrium with albite was calculated, which defined the composition of the initial melt aliquot. The volume of the melt inclusion (constant in all subsequent steps) was calculated according to the specific volume of melt and the mass of the aliquot. In each subsequent step, a portion of melt (arbitrarily set to $1 \%$ of the albitic component of the initial melt) was crystallized. Consequently, the remaining melt was enriched in $\mathrm{CO}_{2}$ and $\mathrm{H}_{2} \mathrm{O}$ via subtraction of $\mathrm{NaAlSi}_{3} \mathrm{O}_{8}$ into newly-formed albite (i.e., PEC). However, because the melt was initially vapor-saturated, enrichment in $\mathrm{CO}_{2}$ and $\mathrm{H}_{2} \mathrm{O}$ drives the melt towards supersaturation, and some portion of $\mathrm{CO}_{2}$ and $\mathrm{H}_{2} \mathrm{O}$ must be released into a free vapor phase, or bubble. In a closed system, at any given temperature and pressure the $\mathrm{CO}_{2} / \mathrm{H}_{2} \mathrm{O}$ ratio of the exsolved vapor phase is constrained by the $\mathrm{CO}_{2} / \mathrm{H}_{2} \mathrm{O}$ ratio in the coexisting melt, and an iterative 
181 procedure is employed to solve for melt-vapor equilibrium. The density and volume of the 182 exsolved vapor phase was calculated using the Redlich-Kwong equation of state (Redlich and 183 Kwong, 1949) with the parameters of Holloway (1977). To achieve constant volume conditions, 184 a nested iterative procedure was also employed to adjust internal pressure (with temperature 185 constrained by the vapor-saturated liquidus surface). Note that in the latter isochoric constraint, 186 the volume of the inclusion was defined by the sum of volumes of melt plus vapor plus albite 187 formed during PEC (i.e., albite crystallized on the walls of the inclusion). The two constraints 188 (mass balance and isochoricity) were solved simultaneously for each increment of PEC, to obtain 189 a trajectory of evolving pressure-temperature-composition (melt+vapor) conditions. The 190 calculations did not treat external pressure as a variable, nor did they account for compressibility 191 of the host mineral.

192 In addition to the simulations using an albitic melt composition trapped in albite, we 193 conducted several simulations using a basaltic melt composition trapped in olivine. The 194 solubility model for volatile species in the basaltic melt (based on an average tholeiitic basalt 195 composition) was from Holloway and Blank (1984). The volumetric properties of the basaltic 196 melt, as well as the volume of fusion of olivine, were modeled based on the data of Lange and 197 Carmichael (1990). Effect of $\mathrm{H}_{2} \mathrm{O}$ on the olivine crystallization temperature was modeled based 198 on the data of Almeev et al. (2007). Our model is thus somewhat simplified and does not invoke 199 compositional changes or effects in the basaltic melt (nor host olivine) but nevertheless serves to 200 compare and contrast the mafic system with the earlier albitic model.

Note that the recent study by Tuohy et al. (2016) reported new numerical modeling showing a greater volume fraction of vapor at equivalent degree of PEC than reported by SteeleMacInnis et al. (2011). The model described by Tuohy et al. (2016) used similar methods to 
204 those used by Steele-MacInnis et al. (2011), but including MI of basaltic composition entrapped in olivine (rather than albitic composition entrapped in albite). The larger volume fractions of vapor predicted for olivine-hosted MI by Tuohy et al. (2016) is consistent with the numerical model of Moore et al. (2015), which also showed that the relative volume contraction during cooling of olivine-hosted MI is significantly greater than that of MI hosted in alkali feldspar (see Fig. 8a versus 8e of Moore et al. 2015). Thus, Moore et al. (2015) stated that among MI trapped in olivine, pyroxenes, feldspars and quartz, the MI trapped in alkali feldspars are expected to exhibit the smallest vapor bubbles, in terms of relative volume fractions. These same effects are reproduced by the model described here, when using the parameters appropriate for a basaltic melt and olivine host. We should note that Steele-MacInnis et al. (2011) stated that the effect of PEC in olivine-hosted MI would be less than that in albite-hosted MI according to a lesser volume of fusion of olivine compared to albite; however, this statement was incorrect because of failure to account for the different stoichiometries of one formula unit of albite versus olivine reported by Lange and Carmichael (1990). When compared at an equivalent 8-oxygen basis (NaAlSi ${ }_{3} \mathrm{O}_{8}$ versus $\left.(\mathrm{Fe}, \mathrm{Mg})_{4} \mathrm{Si}_{2} \mathrm{O}_{8}\right)$, olivine exhibits a greater $\Delta V_{\text {fusion }}$ than albite, which leads to a greater volume fraction of vapor produced in olivine-hosted MI at equivalent degrees of PEC (Moore et al. 2015; Tuohy et al. 2016).

The key addition to the methods described above, for the case of heterogeneously 222 entrapped inclusions, was to set the initial conditions within the MI such that the inclusion 223 initially contained vapor-saturated melt plus a finite volume of trapped vapor. Thus, at the initial 224 pressure-temperature conditions, the composition of vapor in equilibrium with melt was 225 calculated using the model of Holloway and Blank (1994), and an initial mass of $\mathrm{H}_{2} \mathrm{O}$ and $\mathrm{CO}_{2}$ in 226 the vapor phase was defined according to the calculated $\mathrm{CO}_{2} / \mathrm{H}_{2} \mathrm{O}$ ratio. The volume of the 
227 resulting trapped vapor phase was calculated using the Redlich-Kwong equation of state. The combined volume of initial melt plus vapor was then used as the reference volume for constantvolume calculations in all subsequent steps.

We conducted simulations for an albitic melt composition hosted in albite using a trapping temperature and pressure of $930{ }^{\circ} \mathrm{C}$ and $200 \mathrm{MPa}$ (equivalent to the model shown in Fig. 10 of Steele-MacInnis et al. 2011), for 12 starting volume fractions of vapor: 0, 5, 10, 15, 20, 40, 60, 80, 85, 90 and 95 vol.\% vapor. We conducted additional simulations for a basaltic melt composition hosted in olivine using a trapping temperature and pressure of $1200{ }^{\circ} \mathrm{C}$ and 120 $\mathrm{MPa}$, for six starting volume fractions of vapor: $0,5,10,15,20$ and 40 vol.\% vapor. In each simulation, we traced the evolution of $\mathrm{H}_{2} \mathrm{O}$ and $\mathrm{CO}_{2}$ concentrations in the melt, as well as temperature and internal pressure, during PEC up to 10\% (by mass) of the silicate (albitic or basaltic) component of the melt. We modeled up to $10 \%$ PEC because greater degrees of PEC than this are rarely reported in literature (Steele-MacInnis et al. 2011).

\section{RESULTS}

Results of our simulations are shown in Figs. 3 and 4. For the homogeneously entrapped vapor-

243 saturated melt ( 0 vol.\% vapor), the results for the albitic melt are equivalent to those reported by

244 Steele-MacInnis et al. (2011). The basaltic melt hosted in olivine shows a similar trajectory,

245 although the decrease in internal pressure as well as $\mathrm{CO}_{2}$ concentration in the glass is somewhat 246 greater for basaltic MI compared to albitic MI, at equivalent degrees of PEC (Figs. 3B and 4B).

247 Figure 3 also shows heterogeneously entrapped MI with 5-20 vol.\% trapped vapor, and Fig. 4 248 shows heterogeneously entrapped MI with 5-40 vol.\% trapped vapor. Figures 3 and 4 do not 249 show the heterogeneously entrapped MI with higher volume fractions of trapped vapor (up to 
$25095 \% \mathrm{vol} . \%$ ) because the data points and trend lines at these high volume fractions of trapped vapor all overlap.

Figure 3 shows that as the volume fraction of trapped vapor increases, an equivalent degree of PEC is achieved at lower degree of cooling. Stated differently, if a group of MI are all trapped at the same temperature but initially contain various proportions of trapped vapor, those containing more trapped vapor are predicted to undergo more post-entrapment crystallization during the same interval of cooling. We should note that this latter prediction depends upon the assumption of thermodynamic equilibrium, and does not account for potentially differing cooling rates, nor differing glass-transition behavior discussed below. Figure 3 also shows that with increasing volume fraction of trapped vapor, the decrease in internal pressure within an MI concomitant with decreasing temperature/increasing PEC is reduced. Thus, at 10\% PEC (by mass), the albitic inclusion that trapped no vapor has undergone an internal pressure decrease of $\sim 50 \mathrm{MPa}$, whereas the albitic inclusion that trapped 10 vol.\% vapor has undergone only $\sim 5 \mathrm{MPa}$ of pressure decrease. For the albitic inclusion that trapped 20 vol.\% vapor, the pressure decrease at $10 \% \mathrm{PEC}$ is only $\sim 1 \mathrm{MPa}$, and the pressure-temperature trajectory is essentially equivalent to that of the $\mathrm{CO}_{2}-\mathrm{H}_{2} \mathrm{O}$ fluid isochore corresponding to the composition and density of the trapped vapor. Analogous trends are evident in the models for basaltic MI hosted in olivine (Fig. 3B). As PEC, cooling and decompression progress, the silicate melt within the MI gradually exsolves $\mathrm{H}_{2} \mathrm{O}$ and $\mathrm{CO}_{2}$ into the vapor bubble (Steele-MacInnis et al. 2011). However, the concentrations of these volatiles in the remaining melt (glass) phase diverge owing to the orderof-magnitude difference in their solubilities in the melt, versus their relative concentrations in the conjugate vapor phase (Steele-MacInnis et al. 2011). Hence, for the albitic MI that trapped no vapor, after $10 \%$ PEC the $\mathrm{CO}_{2}$ concentration in the melt decreases from 520 to $230 \mathrm{ppm}$, 
whereas the $\mathrm{H}_{2} \mathrm{O}$ concentration in the melt increases from 3.8 to 4.2 wt.\% (Fig. 4). With increasing volume fraction of trapped vapor, these effects are more subdued (Fig. 4). For example, for the albitic MI that traps 10 vol. $\%$ of vapor, at $10 \% \mathrm{PEC}$ the $\mathrm{CO}_{2}$ concentration in the melt has decreased from 520 to $450 \mathrm{ppm}$, and the $\mathrm{H}_{2} \mathrm{O}$ concentration in the melt has increased from 3.8 to 4.0 wt. $\%$. At $\geq 60 \%$ trapped vapor, both the $\mathrm{CO}_{2}$ concentration and the $\mathrm{H}_{2} \mathrm{O}$ concentration in the melt remain essentially constant ( $\sim 520 \mathrm{ppm}$ and $\sim 3.8 \mathrm{wt} . \%$, respectively) up to $10 \%$ PEC. Again, analogous trends are evident for the basaltic MI trapped in olivine (Fig. 4B).

\section{DISCUSSION}

As expected, as the volume fraction of trapped vapor in the melt inclusion increases, the pressure-temperature trajectory followed by the MI during PEC and cooling approaches that of a coeval $\mathrm{CO}_{2}-\mathrm{H}_{2} \mathrm{O}$ fluid-inclusion isochore (Fig. 3). Indeed, at volume fractions of trapped vapor greater than $\sim 20$ vol. $\%$ for the albitic melt, and $\sim 40$ vol. $\%$ for the basaltic melt, the pressuretemperature trajectory of the MI is indistinguishable from a coeval fluid-inclusion isochore. Consequently, the internal pressure decreases more gradually in inclusions containing more trapped vapor, and thus degassing of $\mathrm{CO}_{2}$ and $\mathrm{H}_{2} \mathrm{O}$ into the vapor bubble is more subdued. Hence, the volatile concentrations in the melt show less change from the initial composition at equivalent degrees of PEC, in inclusions containing more trapped vapor. In the extreme case of $>60$ vol.\% trapped vapor, the concentrations of $\mathrm{CO}_{2}$ and $\mathrm{H}_{2} \mathrm{O}$ in the melt (and thus, in the glass in quenched MI) are predicted to be equal within the uncertainty of standard analytical techniques to those in the originally trapped melt.

As the volume fraction of trapped vapor increases, we also see a decrease in the degree of cooling required to achieve an equivalent degree of PEC (Fig. 3). This phenomenon is a result of 
mass-balance constraints on the vapor-saturated solidus temperature of the MI. According to Burnham and Davis (1974), the solidus temperature of a vapor-saturated albitic melt is a function of the ratio of $\mathrm{H}_{2} \mathrm{O}$ to $\mathrm{CO}_{2}$ in the vapor phase. In a melt inclusion which traps only vaporsaturated melt (with no trapped vapor), the composition of the vapor phase becomes increasingly enriched in $\mathrm{H}_{2} \mathrm{O}$ during cooling and PEC (i.e., the composition of each aliquot of exsolved vapor is more $\mathrm{H}_{2} \mathrm{O}$-rich at each increment of PEC). Because this inclusion traps only a vapor-saturated melt, and because the $\mathrm{H}_{2} \mathrm{O}$ concentration in such a melt is commonly an order of magnitude greater than the $\mathrm{CO}_{2}$ concentration, the inclusion is able to achieve a very $\mathrm{H}_{2} \mathrm{O}$-rich vapor bubble at the later stages of degassing of $\mathrm{H}_{2} \mathrm{O}$. As such, as cooling and PEC occur, the vapor-saturated solidus temperature is increasingly depressed, allowing PEC to proceed towards the $\mathrm{H}_{2} \mathrm{O}$ saturated solidus (Burnham and Davis 1974). In contrast, melt inclusions that trap a vapor bubble have their volatile budgets buffered by the composition of the trapped vapor, which is commonly significantly more $\mathrm{CO}_{2}$-rich than the corresponding melt phase. Inclusions that trap a large proportion of vapor thus have higher vapor-saturated solidus temperatures, and may undergo an equivalent degree of PEC in a smaller temperature interval. In the extreme case of an inclusion that traps $\geq 60$ vol.\% vapor, the vapor-saturated solidus temperature is approximately equal to the 312 trapping temperature, and the melt may undergo some amount of PEC nearly isothermally. 313 Notably, this process may induce variation in the measured major-element composition of the 314 glass phase within MI containing different proportions of trapped vapor.

317 behavior. As noted above, our numerical model assumes thermodynamic equilibrium, and thus 318 the glass transition is not included explicitly in our results. Nevertheless, we can make some 
342 initial volatile concentrations of $3.8 \mathrm{wt} . \% \mathrm{H}_{2} \mathrm{O}$ and $520 \mathrm{ppm} \mathrm{CO}_{2}$. The basaltic melt simulations used initial conditions of $1200{ }^{\circ} \mathrm{C}, 120 \mathrm{MPa}$, and initial volatile concentrations of 0.95 wt. $\% \mathrm{H}_{2} \mathrm{O}$ and $535 \mathrm{ppm} \mathrm{CO}_{2}$. One interesting question to consider is how the predicted trends in PEC and volatile evolution within the MI may vary with different initial conditions. Steele-MacInnis et al. (2011) reported that $\mathrm{CO}_{2}$-absent $\mathrm{MI}$ containing only dissolved $\mathrm{H}_{2} \mathrm{O}$ undergo immediate and sustained pressure increase with decreasing temperature and $\mathrm{PEC}$, tracking the $\mathrm{H}_{2} \mathrm{O}$-saturated albitic solidus. Conversely, $\mathrm{H}_{2} \mathrm{O}$-absent, $\mathrm{CO}_{2}$-bearing $\mathrm{MI}$ undergo pressure decrease during cooling and PEC, tracking the $\mathrm{CO}_{2}$-saturated albitic solidus. Inclusions that trap a melt containing dissolved $\mathrm{H}_{2} \mathrm{O}$ plus $\mathrm{CO}_{2}$ follow trends that are initially more similar to the $\mathrm{CO}_{2}$ endmember, and evolve towards more $\mathrm{H}_{2} \mathrm{O}$-dominated trends as $\mathrm{PEC}$ and cooling progress (Steele-MacInnis et al. 2011). We expect that the results of simulations included here, for MI that trap vapor along with the melt, can be extended to other initial conditions, with the only major difference being the initial trajectory of MI which trap little or no vapor. Regardless of the initial conditions and initial $\mathrm{H}_{2} \mathrm{O}-\mathrm{CO}_{2}$ concentrations of the trapped melt \pm vapor, inclusions trapping a high proportion of vapor are expected to conform to a $P-T$ trajectory resembling the isochore of the vapor phase. However, it must be stressed that additional processes such as diffusive reequilibration or decrepitation, which are not modeled here, may cause deviation from this model $P$ - $T$ trajectory. Some of these factors are discussed briefly below.

Examples of photomicrographs showing MI with anomalously large (>10 vol.\%) bubbles are fairly common in the literature, but it should be stressed that based on photomicrographs alone it is commonly impossible to differentiate large bubbles generated by heterogeneous entrapment versus other processes, such as diffusive reequilibration (Gaetani et al. 2012; Bucholz et al. 2013) or stretching, leakage and/or decrepitation (Maclennan, 2017). In addition, 
365 based on photomicrographs alone it is impossible to determine the volume of glass polished away during sample preparation, as well as if any additional bubble(s) was polished away to exposed the MI at the sample surface. Moreover, photomicrographs are sometimes unrevealing in terms of whether MI exposed by polishing were originally fully enclosed, or rather connected to the exterior ("hourglass inclusions") - in the latter scenario, bubble formation can accompany evacuation of some of the melt to the exterior during decompression (Anderson 1991). Thus, we advocate an approach using coeval assemblages of melt inclusions (Fig. 1A), and using additional petrologic indicators to test for timing and post-entrapment modifications of MI (e.g., Hartley et al. 2015). In the following section, we evaluate evidence for heterogeneous entrapment in the two datasets of Hartley et al. (2014) and Moore et al. (2015).

Few analytical data are available in literature on the $\mathrm{H}_{2} \mathrm{O}$ and $\mathrm{CO}_{2}$ concentrations of the glass phase within inclusions containing significant trapped vapor. This probably reflects to some extent that such inclusions are deliberately not targeted for microanalysis because of their anomalously large bubbles. Moreover, analysis of glass in such inclusions may be difficult because of the small analytical volume, for instance in melt-bearing "fluid inclusions" with only a thin film of silicate glass. Our comparison with existing analytical data is therefore limited to vapor bubble $\mathrm{CO}_{2}$ densities from Hartley et al. (2014) and Moore et al. (2015). Both these 382 studies characterized the $\mathrm{CO}_{2}$ density within $\mathrm{MI}$ vapor bubbles using Raman spectroscopy. The 383 MI described in these two studies are shown in Fig. 5, in terms of inclusion volume versus 384 bubble volume (based on the diagrams of Moore et al. 2015 and Aster et al. 2016). Key 385 observations from Fig. 5 are that both datasets include several inclusions with anomalously large 386 vapor bubbles (>10 vol.\%), and that there is no obvious relationship between MI size and bubble 
387 size (see also Fig. 1A). This latter point is consistent with heterogeneous entrapment of vapor in some of the MI, if it is assumed that MI were formed at the same time.

Figure 6A shows the results of the present modeling of an albitic MI, plotted in terms of the density of the vapor bubble versus the vapor volume fraction, for trapped vapor fractions ranging from zero to 95 vol.\%. At low volume fractions of trapped vapor, the density of the vapor bubble decreases abruptly with relatively low degrees of PEC. In contrast, at higher volume fractions of trapped vapor, PEC up to $10 \%$ has essentially no effect on the density of the vapor phase. The grey-shaded field on Fig. 6A thus delimits a distribution of bubble density versus volume fraction, corresponding to MI that trap various proportions of vapor and undergo various degrees of PEC up to $10 \%$, with the assumption that all MI were trapped at the same pressure-temperature conditions and with the same $\mathrm{H}_{2} \mathrm{O}$ and $\mathrm{CO}_{2}$ concentrations in the trapped melt.

Figures 6B shows the data of Hartley et al. (2014), on MI bubbles hosted in olivine from the AD 1783-1784 Laki eruption, southeast Iceland. Figure 6C shows the data of Moore et al. (2015) on MI bubbles hosted in olivine from the 1959 Kilauea Iki and 1960 Kapoho eruptions, Hawaii. Both of these datasets show a similar distribution: Most of the data are clustered towards relatively low volume fractions of vapor up to $\sim 5-10$ vol. $\%$, and within this range the vapor densities show a wide range of variability. However, a small number of MI show much higher volume fraction of vapor up to $100 \mathrm{vol} . \%$, and these MI also show variable, but generally higher densities. For example, the majority of the MI measured by Hartley et al. (2014) contain $<10$ vol.\% vapor and have vapor densities range from $<50$ to $\sim 250 \mathrm{~kg} / \mathrm{m}^{3}$. In contrast, among the MI with $>10$ vol.\% vapor, densities range from $\sim 100$ to $\sim 300 \mathrm{~kg} / \mathrm{m}^{3}$. Notice also that the lowest vapor density occurs at low volume fraction of vapor, whereas the highest vapor density occurs 
410 at the highest volume fraction of vapor. The data of Moore et al. (2015) similarly show a greater 411 variation in vapor density at low volume fractions of vapor, compared to generally more

412 consistent vapor densities at volume fractions $>10$ vol. \%. Moreover, the densities of vapor 413 bubbles that comprise $>10$ vol.\% in the data of Moore et al. (2015) cluster around $\sim 130 \mathrm{~kg} / \mathrm{m}^{3}$, 414 which is around the maximum of the low-volume fraction cluster of data. The grey-shaded 415 regions in Figs. 6B and 6C were constructed using the same numerical methods described above, 416 assuming a basaltic melt composition hosted in olivine. Initial conditions for the modeling in Fig. 417 6B were $1210{ }^{\circ} \mathrm{C}$ and $85 \mathrm{MPa}$, whereas the initial conditions for the modeling in Fig. $6 \mathrm{C}$ were $4181210{ }^{\circ} \mathrm{C}$ and $45 \mathrm{MPa}$. In both cases, the initial (trapping) pressures are less than those 419 constrained by $\mathrm{H}_{2} \mathrm{O}-\mathrm{CO}_{2}$ solubility calculations (Hartley et al. 2014; Moore et al. 2015) in order 420 to match the relatively low density of the vapor bubbles. Stated differently, these initial pressures 421 were selected according to the pressure on the relevant $\mathrm{CO}_{2}-\mathrm{H}_{2} \mathrm{O}$ isochore at the presumed 422 trapping temperature of $1210^{\circ} \mathrm{C}$. The discrepancy in modeled initial pressure versus inferred 423 trapping pressure for the studied MI likely reflects expansion (and concomitant decrease in 424 density) of the vapor bubble during quenching of the glass (Esposito et al., 2011), or vapor loss 425 by decrepitation (Maclennan, 2017). Nevertheless, in both cases the predicted trends for MI that 426 trapped some fraction of vapor and subsequently underwent various degrees of PEC are broadly 427 consistent with the analytical data. Certainly, these results do not provide definitive evidence of a 428 role of heterogeneous trapping and PEC in the distribution of data from Laki, Kilauea Iki and 429 Kapoho, but the results are at least consonant with this general model. However, we stress once again that this interpretation relies on the assumption that the MI shown in Figs. $6 \mathrm{~B}$ or $6 \mathrm{C}$ were 431 trapped coevally, whereas we lack petrographic information to test this assumption. 
The recent study of Aster et al. (2016) provides another dataset on MI vapor bubble densities and volume fractions from four cinder cones: two in the Cascade Arc and two in the Trans-Mexico volcanic belt. Aster et al. (2016) only report vapor bubbles occupying up to 15 vol.\% of the MI. The densities of vapor bubbles measured by Aster et al. (2016) do not show any systematic relationship with bubble volume fraction. They inferred heterogeneous entrapment of some of the vapor bubbles by calculating the maximum expected volume fraction of vapor produced by cooling, PEC and quenching of the MI, and determined that most of the bubbles could have formed by these processes alone (i.e., without heterogeneous trapping of vapor).

These results by Aster et al. (2016) indicate that the predictions made in the present study do not always apply to olivine-hosted MI, such as in the case when only bubbles up to $\sim 15$ vol.\% are observed. Nevertheless, the comparison with the datasets of Hartley et al. (2014) and Moore et al. (2015) indicate that bubbles with larger volume fractions (up to 100 vol.\%) occur in olivinehosted MI from volcanic systems, and MI hosting such bubbles may be amenable for analysis of pre-eruptive volatile concentrations.

The comparison of our model predictions with these literature data from Hartley et al. (2014) and Moore et al. (2015) are not unequivocal, partly because of sparseness and scatter in the data, and likely also because various factors affect the vapor densities of olivine-hosted MI. For example, MI may have been trapped at various depths, and certainly re-equilibration of volatile constituents is likely to play a role. Hartley et al. (2015) used the $\mathrm{H}_{2} \mathrm{O} / \mathrm{Ce}$ ratios of some of the same MI discussed here, to evaluate the degree of $\mathrm{H}_{2} \mathrm{O}$ loss or gain by diffusion. This type of analysis could in principle be used to help constrain the degree of re-equilibration of MI containing anomalously large bubbles, but such inclusions were not analyzed by Hartley et al. (2015). An additional complication is that MI that trap relatively small volume fractions of vapor 
55 may not exhibit anomalously large vapor bubbles (Aster et al. 2016). In some cases, trapping of vapor may be only distinguishable by calculating the volume fraction of vapor formed via preeruptive cooling coupled with the effects of cooling and quenching to the glass transition temperature (Aster et al. 2016). Nevertheless, the data shown in Figs. 5 and 6 are broadly consistent with the prediction that MI which trapped significant proportions of vapor can maintain a relatively high vapor density at room temperature, compared to inclusions that trapped little to no vapor. A corollary of this prediction is that the glass phase in such inclusions is expected to retain concentrations of $\mathrm{H}_{2} \mathrm{O}$ and $\mathrm{CO}_{2}$ that reflect the composition of the melt at the time of trapping. As such, these data and model predictions suggest that microanalysis of the glass phase within MI containing trapped vapor may be an amenable method to directly sample the $\mathrm{H}_{2} \mathrm{O}$ and $\mathrm{CO}_{2}$ concentrations of the trapped melt, independently of PEC. Moreover, analysis of the $\mathrm{CO}_{2}$ and $\mathrm{H}_{2} \mathrm{O}$ concentrations in the corresponding (heterogeneously entrapped) vapor bubble using the methods developed by Esposito et al. (2016) may be an amenable and complementary method to determine the composition of the coeval, equilibrium magmatic vapor phase.

In interpreting the patterns in vapor density versus volume fraction in Fig. 6, we must 471 emphasize that the available data do not permit us to evaluate whether the MI record coeval 472 entrapment. As such, it is not currently possible to verify whether the MI in Fig. 6 record similar 473 physical and chemical conditions of trapping. The best method to constrain the relative timing of 474 MI trapping would be to study MI in the context of coeval assemblages (Esposito et al. 2014). In 475 the case of melt inclusions from a single eruptive event in which suitable assemblages are absent, 476 an alternative method would be to categorize MI based on the forsterite content of the 477 immediately adjacent host olivine, or the major element composition of the MI, or some 
478 combination of these parameters. Such procedures may allow us to better define the trends of melt-volatile composition with trapped vapor fraction. Similarly, direct analysis of the $\mathrm{CO}_{2}$ and $\mathrm{H}_{2} \mathrm{O}$ concentrations in the glass phase of MI containing anomalously large bubbles would be extremely beneficial to assess the model predictions described here. Unfortunately, the available data do not allow us to assess these various potential indicators for coeval trapping (as well as for potential diffusive reequilibration, etc.) - we hope that future studies will provide additional constraints to evaluate these various factors.

Another potential issue that may influence trends such as those shown in Fig. 5B and 5C is the precipitation of carbonate at the glass/bubble interface (e.g., Kamenetsky et al. 2001; Moore et al. 2015; Esposito et al. 2016), which will lower the $\mathrm{CO}_{2}$ density measured in the bubble. It is important to note that Kamenetsky et al. (2001) showed a positive correlation between the relative volume fraction of the vapor bubble and the amount of precipitates at the glass/bubble interface.

A final caveat that must be addressed is the possibility of forming large vapor bubbles within MI by processes other than heterogeneous entrapment, namely bubble growth as a result of $\mathrm{H}^{+}$diffusion or following stretching, leakage and/or decrepitation. Hydrogen diffusion will result in an increased density (decreased molar volume) of the melt phase, which can result in formation of a bubble by contraction of the melt. Similarly, stretching, leakage and/or decrepitation may effectively reduce the bulk density (increase the bulk molar volume) of the inclusion, thereby favoring the subsequent production of large bubbles. Regarding $\mathrm{H}^{+}$diffusion, we calculated the volume fraction of vapor that would be expected in a basaltic melt inclusion with a starting $\mathrm{H}_{2} \mathrm{O}$ concentration of 5 wt.\%, assuming different proportions of $\mathrm{H}_{2} \mathrm{O}$ loss, according to the effect of $\mathrm{H}_{2} \mathrm{O}$ on the density of the silicate glass (Lange and Carmichael 1987; 
1990; Ochs and Lange 1999; Iacovino 2014). Our calculation was based on a basaltic melt trapped at $100 \mathrm{MPa}$ and $1100{ }^{\circ} \mathrm{C}$. In this example, if the $\mathrm{H}_{2} \mathrm{O}$ concentration is reduced to 4 wt. $\%$ by diffusive reequilibration, then the expected volume fraction of vapor would be $\sim 2$ vol.\%. In the extreme case where all $\mathrm{H}_{2} \mathrm{O}$ was lost (resulting in an anhydrous glass) then the maximum volume fraction of the shrinkage bubble would be $\sim 9$ vol.\%. As such, bubbles exceeding 2-9 vol.\% vapor (e.g., Figs. 5 and 6) suggest additional factors besides diffusive reequilibration. We note that $\mathrm{H}_{2} \mathrm{O} / \mathrm{Ce}$ data (e.g., Hartley et al. 2015) and hydrogen isotopic analyses of MI glasses may add constraints to evaluate the extent of diffusive reequilibration in future studies. Stretching, leakage and decrepitation (SLD) may all be induced by internal overpressure within the inclusion during exhumation and cooling (Maclennan, 2017), analogous to the same phenomena in aqueous fluid inclusions (Bodnar et al. 1989). In some cases in which SLD occurs as a result of brittle deformation (cracking) of the mineral host, it may be possible to identify signs of fluid loss from melt inclusions based on the presence of annealed cracks or decrepitation halos (e.g., Fig. 3b in Cannatelli et al., 2015). Although we did not consider or account for stretching, leakage or decrepitation in this study, we do not mean to suggest that all large bubbles in inclusions are generated by heterogeneous trapping, and indeed we expect that some MI containing large bubbles may reflect SLD. In particular, MI trapped at high pressures (which 518 thus exsolve a high-density $\mathrm{CO}_{2}-\mathrm{H}_{2} \mathrm{O}$ fluid phase during $\mathrm{PEC}$ and cooling) may be particularly 519 susceptible to SLD because of the potential for internal overpressure of the high-density, $\mathrm{CO}_{2}$ 520 rich fluid (Maclennan, 2017). Again, this suggestion is based on the experience of high-density, $\mathrm{CO}_{2}$-bearing fluid inclusions, which are susceptible to high internal pressures and, thus, decrepitation (Diamond, 2001). Importantly, the trends expected from such processes would differ from those predicted in the case of heterogeneous entrapment. Specifically, the density of 


\section{REFERENCES}

Aster EM, Wallace PJ, Moore LR, Watkins J, Gazel E, Bodnar RJ (2016) Reconstructing $\mathrm{CO}_{2}$ concentrations in basaltic melt inclusions using Raman analysis of vapor bubbles. $\mathbf{J}$ Volcanol Geoth Res 323:148-162

Almeev RR, Holtz F, Koepke J, Parat F, Botcharnikov RE (2007) The effect of $\mathrm{H}_{2} \mathrm{O}$ on olivine crystallization in MORB: Experimental calibration at $200 \mathrm{MPa}$. Am Mineral 92: 670-674

Anderson AT (1991) Hourglass inclusions: Theory and application to the Bishop Rhyolitic Tuff. Am Mineral 76:530-547

Anderson AT, Brown GG (1993) $\mathrm{CO}_{2}$ contents and formation pressures of some Kilauean melt inclusions. Am Mineral 78:794-803

Belkin HE, De Vivo B, Roedder E, Cortini M (1985) Fluid inclusion geobarometry from ejected Mt. Somma-Vesuvius nodules. Am Mineral 70:288-303

Belkin HE, De Vivo B (1993) Fluid inclusion studies of ejected nodules from plinian eruptions of Mt. Somma-Vesuvius. J Volcanol Geoth Res 58:89-100

Bodnar RJ, Binns PR, Hall DL (1989) Synthetic fluid inclusions - VI. Quantitative evaluation of the decrepitation behaviour of fluid inclusions in quartz at one atmosphere confining pressure. J Metamorphic Geol 7:229-242

Bodnar RJ, Student JJ (2006) Melt inclusions in plutonic rocks: Petrography and microthermometry. In: Webster JD (ed) Melt Inclusions in Plutonic Rocks, Mineralogical Association of Canada Short Course Series Volume 36. pp 1-26

Bucholz CE, Gaetani GA, Behn MD, Shimizu N (2013) Post-entrapment modification of volatiles and oxygen fugacity in olivine-hosted melt inclusions. Earth Planet Sci Lett 374:145-155

Burnham CW, Davis NF (1971) The role of $\mathrm{H}_{2} \mathrm{O}$ in silicate melts: I. P-V-T relations in the system $\mathrm{NaAlSi}_{3} \mathrm{O}_{8}-\mathrm{H}_{2} \mathrm{O}$ to 10 kilobars and $1000^{\circ} \mathrm{C}$. Am J Sci 270:54-79

Burnham CW, Davis NF (1974) The role of $\mathrm{H}_{2} \mathrm{O}$ in silicate melts: II. Thermodynamic and phase relations in the system $\mathrm{NaAlSi}_{3} \mathrm{O}_{8}-\mathrm{H}_{2} \mathrm{O}$ to 10 kilobars, $700^{\circ}$ to $1100^{\circ} \mathrm{C}$. Am J Sci 274:902-940

Cannatelli C, Doherty AL, Esposito R, Lima A, De Vivo B (2016) Understanding a volcano through a droplet: A melt inclusion approach. J Geochem Explor 171:4-19

Connolly JAD, Bodnar RJ (1983) A modified Redlich-Kwong equation of state for $\mathrm{H}_{2} \mathrm{O}-\mathrm{CO}_{2}$ mixtures: Application to fluid inclusion studies. EOS Transactions 64:350

Danyushevsky LV, Della Pasqua FN, Sokolov S (2000) Re-equilibration of melt inclusions trapped by magnesian olivine phenocrysts from subduction-related magmas; petrological implications. Contrib Mineral Petr 138:68-83

Diamond LW (2003) Introduction to gas-bearing, aqueous fluid inclusions. In: Samson I, Anderson A, Marshall D (eds) Fluid Inclusions Analysis and Interpretation, Mineralogical Association of Canada Short Course Series Volume 32. pp 101-158

Esposito R, Bodnar RJ, Danyushevsky LV, De Vivo B, Fedele L, Hunter J, Lima A, Shimizu N, (2011) Volatile evolution of magma associated with the Solchiaro eruption in the Phlegrean Volcanic District (Italy). J Petrol 52:2431-2460

Esposito R, Hunter J, Schiffbauer JD, Shimizu N, Bodnar RJ (2014) An assessment of the reliability of melt inclusions as recorders of the pre-eruptive volatile content of magmas. Am Mineral 99:976-998

Esposito R, Lamadrid HM, Redi D, Steele-MacInnis M, Bodnar RJ, Manning CE, De Vivo B, Cannatelli C, Lima A (2016) Detection of liquid $\mathrm{H}_{2} \mathrm{O}$ in vapor bubbles in reheated melt 
inclusions: implications for magmatic fluid composition and volatile budgets of magmas. Am Mineral 101:1691-1695

Gaetani GA, O'Leary JA, Shimizu N, Bucholz CE, Newville M (2012) Rapid reequilibration of $\mathrm{H}_{2} \mathrm{O}$ and oxygen fugacity in olivine-hosted melt inclusions. Geology 40:915-918

Giordano D, Potuzak M, Romano C, Dingwell DB, Nowak M (2008) Viscosity and glass transition temperature of hydrous melts in the system $\mathrm{CaAl}_{2} \mathrm{Si}_{2} \mathrm{O}_{8}-\mathrm{CaMgSi}_{2} \mathrm{O}_{6}$. Chem Geol 256:203-215

Harris AC, Kamenetsky VS, White NC, van Achterbergh E, Ryan CG (2003) Melt incluions in veins: Linking magmas and porphyry $\mathrm{Cu}$ deposits. Science 302:2109-2111

Hartley ME, Maclennan J, Edmonds M, Thordarson T (2014) Reconstructing the deep $\mathrm{CO}_{2}$ degassing behaviour of large basaltic fissure eruptions. Earth Planet Sci Lett 393:120-131

Hartley ME, Neave DA, Maclennan J, Edmonds M, Thordarson T (2015) Diffusive overhydration of olivine-hosted melt inclusions. Earth Planet Sci Lett 425:168-178

Holloway JR (1977) Fugacity and activity of molecular species in supercritical fluids. In: Fraser DG (ed) Thermodynamics in Geology. Reidel, Dordrecht. pp 161-181.

Holloway JR (1987) Igneous fluids. Rev Mineral 17:211-233

Holloway JR, Blank JG (1994) Application of experimental results to C-O-H species in natural melts. Rev Mineral 30:187-230

Iacovino K (2014) Glass Density Calc v.3.0. http://www.kaylaiacovino.com/tools-forpetrologists/. Accessed 28 January 2017.

Kamenetsky VS, Binns RA, Gemmell JB, Crawford AJ, Mernagh TP, Maas R, Steele D (2001) Parental basaltic melts and fluids in eastern Manus backarc Basin: implications for hydrothermal mineralisation. Earth Planet Sci Lett 184:685-702

Lange RL, Carmichael ISE (1987) Densities of $\mathrm{Na}_{2} \mathrm{O}-\mathrm{K}_{2} \mathrm{O}-\mathrm{CaO}-\mathrm{MgO}-\mathrm{FeO}-\mathrm{Fe}_{2} \mathrm{O}_{3}-\mathrm{TiO}_{2}-\mathrm{SiO}_{2}$ liquids: new measurements and derived partial molar volumes. Geochim Cosmochim Acta 53:2195-2946

Lange RL, Carmichael ISE (1990) Thermodynamic properties of silicate liquids with emphasis on density, thermal expansion and compressibility. Rev Mineral 24:25-64

Lowenstern JB (1994) Dissolved volatile concentrations in an ore-forming magma. Geology 22:893-896

Lowenstern JB (1995) Applications of silicate-melt inclusions to the study of magmatic volatiles. In: Thompson JFH (ed) Magmas, fluids and ore deposition, Mineralogical Association of Canada Short Course Series Volume 23. pp 71-99

Lowenstern JB (2003) Melt inclusions come of age; volatiles, volcanoes, and Sorby's legacy. In: De Vivo B, Bodnar RJ (eds) Melt Inclusions in Volcanic Systems: Methods, Applications and Problems. Elsevier, Amsterdam. pp 1-21

Maclennan, J (2017) Bubble formation and decrepitation control the CO2 content of olivinehosted melt inclusions. Geochem, Geophys, Geosyst (in press) doi:10.1002/2016GC006633

Métrich N, Wallace PJ (2008) Volatile abundances in basaltic magmas and their degassing paths tracked by melt inclusions. Rev Mineral Geochem 69:363-402

Mironov N, Portnyagin $\mathrm{M}(2011) \mathrm{H}_{2} \mathrm{O}$ and $\mathrm{CO}_{2}$ in parental magmas of Kliuchevskoi volcano inferred from study of melt and fluid inclusions in olivine. Russ Geol Geophys 52:13531367

Mironov N, Portnyagin M, Botcharnikov R, Gurenko A, Hoernle K, Holtz F (2015) Quantification of the $\mathrm{CO}_{2}$ budget and $\mathrm{H}_{2} \mathrm{O}-\mathrm{CO}_{2}$ systematics in subduction-zone magmas 
through the experimental hydration of melt inclusions in olivine at high $\mathrm{H}_{2} \mathrm{O}$ pressure. Earth Planet Sci Lett 425:1-11

Moore LR, Gazel E, Tuohy R, Lloyd AS, Esposito R, Steele-MacInnis M, Hauri EH, Wallace PJ, Plank T, Bodnar RJ (2015) Bubbles matter: An assessment of the contribution of vapor bubbles to melt inclusion volatile budgets. Am Mineral 100:806-823

Newman S, Lowenstern JB (2002) VOLATILECALC: A silicate melt- $\mathrm{H}_{2} \mathrm{O}-\mathrm{CO}_{2}$ solution model written in Visual Basic for excel. Chem Geol 28:597-604

Ochs FA, Lange RA (1999) The density of hydrous magmatic liquids. Science 283:1314-1317

Papale P, Moretti R, Barbato D (2006) The compositional dependence of the saturation surface of $\mathrm{H}_{2} \mathrm{O}+\mathrm{CO}_{2}$ fluids in silicate melts. Chem Geol 229:78-95

Portnyagin M, Almeev R, Matveev S, Holtz F (2008) Experimental evidence for rapid water exchange between melt inclusions in olivine and host magma. Earth Planet Sci Lett 272:541-552

Qin Z, Lu F, Anderson AT (1992) Diffusive reequilibration of melt and fluid inclusions. Am Mineral 77:565-576

Redlich O, Kwong JNS (1949) On the thermodynamics of solutions. Chem Rev 44:233-244

Schiavi F, Provost A, Schiano P, Cluzel N (2016) P-V-T-X evolution of olivine-hosted melt inclusions during high-temperature homogenization treatment. Geochim Cosmochim Acta 172:1-21

Shishkina TA, Botcharnikov RE, Holtz F, Almeev R, Jazwa AM, Jakubiak AA (2014) Compositional and pressure effects on the solubility of $\mathrm{H}_{2} \mathrm{O}$ and $\mathrm{CO}_{2}$ in mafic melts. Chem Geol 388:112-129

Steele-MacInnis M, Esposito R, Bodnar RJ (2011) Thermodynamic model for the effect of postentrapment crystallization on the $\mathrm{H}_{2} \mathrm{O}-\mathrm{CO}_{2}$ systematics of vapor-saturated, silicate melt inclusions. J Petrol 52:2461-2482

Stefanova E, Driesner T, Zajacz Z, Heinrich CA, Petrov P, Vasilev Z (2014) Melt and fluid inclusions in hydrothermal veins: The magmatic to hydrothermal evolution of the Elatsite porphyry Cu-Au deposit, Bulgaria. Econ Geol 109:1359-1381

Sterner SM, Bodnar RJ (1991) Synthetic fluid inclusions. X: Experimental determination of P-V$\mathrm{T}$-X properties in the $\mathrm{CO}_{2}-\mathrm{H}_{2} \mathrm{O}$ system to $6 \mathrm{~kb}$ and $700^{\circ} \mathrm{C}$. Am J Sci 291:1-54

Student JJ, Bodnar RJ (1996) Melt inclusion microthermometry; petrologic constraints from the $\mathrm{H}_{2} \mathrm{O}$-saturated haplogranite system. Petrology 4:291-306

Student JJ, Bodnar RJ (2004) Silicate melt inclusions in porphyry copper deposits; identification and homogenization behavior. Can Mineral 42:1583-1599

Tuohy, RM, Wallace PJ, Loewen MW, Swanson DA, Kent AJR (2016) Magma transport and olivine crystallization depths in Kîlauea's east rift zone inferred from experimentally rehomogenized melt inclusions. Geochim Cosmochim Acta 185:232-250

Wallace PJ, Kamenetsky VS, Cervantes P (2015) Melt inclusion $\mathrm{CO}_{2}$ contents, pressures of olivine crystallization, and the problem of shrinkage bubbles. Am Mineral 100:787-794

Zajacz Z, Halter WE, Pettke T, Guillong M (2008) Determination of fluid/melt partition coefficients by LA-ICPMS analysis of co-existing fluid and silicate melt inclusions: Controls on element partitioning. Geochim Cosmochim Acta 72:2169-2197

Zanon V, Frezzotti ML (2013) Magma storage and ascent conditions beneath Pico and Faial islands (Azores archipelago): A study on fluid inclusions. Geochem Geophys Geosyst $14: 3494-3514$ 
Zanon V, Pimentel A (2015) Spatio-temporal constraints on magma storage and ascent conditions in a transtensional setting: The case of Terceira Island (Azores). Am Mineral 100:795-805 


\section{Figure Captions:}

Fig 1 Assemblages of heterogeneously trapped inclusions of melt plus magmatic vapor exhibit a wide range in the relative volume of vapor bubbles including anomalously high ( $>5 \mathrm{vol} . \%)$ volume fractions of vapor. The transmitted light photomicrographs show: (A) An assemblage and (B) a group of olivine-hosted of silicate melt inclusions from the 1959 eruption of Kilauea Iki, Hawaii (Moore et al., 2015); (C) olivine-hosted MI from the 1783-84 Laki eruption, Iceland (Hartley et al., 2014); (D) an assemblage and (E) a group of plagioclase-hosted MI from the 1783-84 Laki eruption, Iceland. Arrows in panels A, B, C and E indicate inclusions with different volume fractions of vapor (labelled). Notice the variable proportions of vapor, including anomalously large bubbles, in the assemblage shown in (A) suggesting heterogeneous entrapment. The color differences between $\mathrm{MI}$ in (C) probably reflect variations in light scattering between inclusions of different size

Fig. 2 Heterogeneously trapped inclusions of melt plus magmatic vapor follow pressuretemperature trajectories intermediate between those of coeval vapor-saturated melt inclusions and magmatic $\mathrm{CO}_{2}-\mathrm{H}_{2} \mathrm{O}$ fluid inclusions. The pressure-temperature phase diagram shows the vapor-saturated solidus-liquidus of albitic melt contoured by activity of $\mathrm{H}_{2} \mathrm{O}$ (Burnham and Davis 1974) and the liquid-vapor solvus and isochores of a $\mathrm{CO}_{2}-\mathrm{H}_{2} \mathrm{O}$ fluid of $40 \mathrm{~mol} . \% \mathrm{CO}_{2}$ (Connolly and Bodnar 1983). This fluid composition corresponds to the vapor in equilibrium with albitic melt at the trapping condition of $930{ }^{\circ} \mathrm{C}$ and $200 \mathrm{MPa}$, indicated by the star. Path "a" represents the isochore of a $\mathrm{CO}_{2}-\mathrm{H}_{2} \mathrm{O}$ fluid inclusion trapped at this condition, whereas path "b" represents the pressure-temperature trajectory followed by a melt inclusion which trapped only vapor-saturated melt during cooling and PEC. Heterogeneously trapped melt+vapor inclusions are expected to follow a pressure-temperature trajectory intermediate between these two endmembers, exemplified by path "c." Shaded box expanded in Fig. 3A

Fig. 3 Melt inclusions that trap vapor undergo subdued decompression during cooling and PEC. Model results for (A) an albitic melt trapped in albite at $930{ }^{\circ} \mathrm{C}$ and $200 \mathrm{MPa}$, and (B) a basaltic melt trapped in olivine at $1200{ }^{\circ} \mathrm{C}$ and $120 \mathrm{MPa}$. The results of our numerical model show that with increasing volume fraction of trapped vapor, the pressure-temperature pathway followed by the MI approaches that of the coeval $\mathrm{CO}_{2}-\mathrm{H}_{2} \mathrm{O}$ fluid inclusion (indicated by 100 vol.\% vapor, and corresponding to the fluid-inclusion isochore). At $\geq 20$ vol.\% trapped vapor, the pressuretemperature path for the albitic MI is virtually indistinguishable from the fluid-inclusion isochore. Symbols on each curve represent 1\% increments of PEC

Fig. $4 \mathrm{CO}_{2}-\mathrm{H}_{2} \mathrm{O}$ systematics of vapor-saturated $\mathrm{MI}$ during PEC vary with the proportion of trapped vapor. Model results for (A) an albitic melt trapped in albite at $930{ }^{\circ} \mathrm{C}$ and $200 \mathrm{MPa}$, and (B) a basaltic melt trapped in olivine at $1200{ }^{\circ} \mathrm{C}$ and $120 \mathrm{MPa}$. The inclusions that trapped only vapor-saturated melt ( $0 \%$ trapped vapor) undergo the most significant decrease in $\mathrm{CO}_{2}$ content in the melt, whereas MI that trapped more vapor experience less $\mathrm{CO}_{2}$ loss from the melt, for both albitic and basaltic MI. Symbols on each curve represent $1 \%$ increments of PEC

Fig. 4 Volumes of vapor bubbles versus volumes of melt inclusions from (a) the AD 1783-84 Laki eruption, Iceland (Hartley et al. 2014), and (b) the 1959 Kilauea Iki and 1960 Kapoho eruptions, Hawaii (Moore et al. 2015). 
Fig. 6 Densities of MI vapor bubbles vary systematically with the proportion of trapped vapor. (a) Results of our numerical model. (B) MI from the AD 1783-84 Laki eruption, Iceland (Hartley et al. 2014). (C) MI from the 1959 Kilauea Iki and 1960 Kapoho eruptions, Hawaii (Moore et al. 2015). The dashed vertical line in (B) and (C) corresponds to 5 vol.\% vapor, representing the cutoff applied by both Hartley et al. (2014) and Moore et al. (2015) to differentiate MI vapor bubbles likely generated by differential thermal contraction and/or PEC ( $<5$ vol.\%) versus bubbles potentially indicating heterogeneous trapping ( $>5 \mathrm{vol} . \%)$. The light shaded regions in (B) and (C) were calculated as described in the text 


\section{$100 \mu \mathrm{m}$

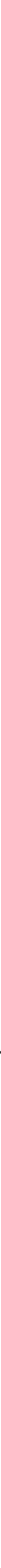

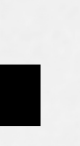

(29- 






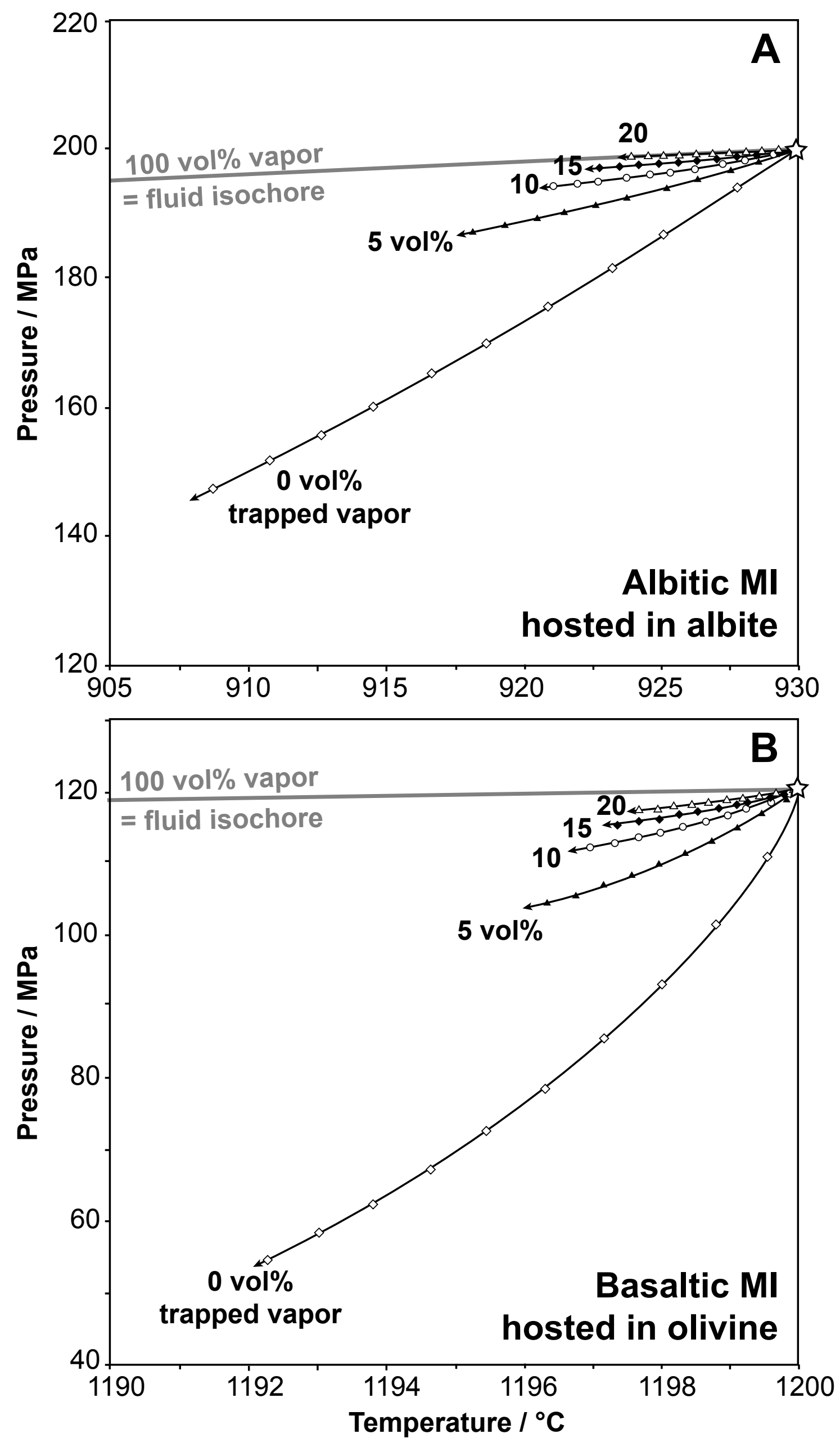


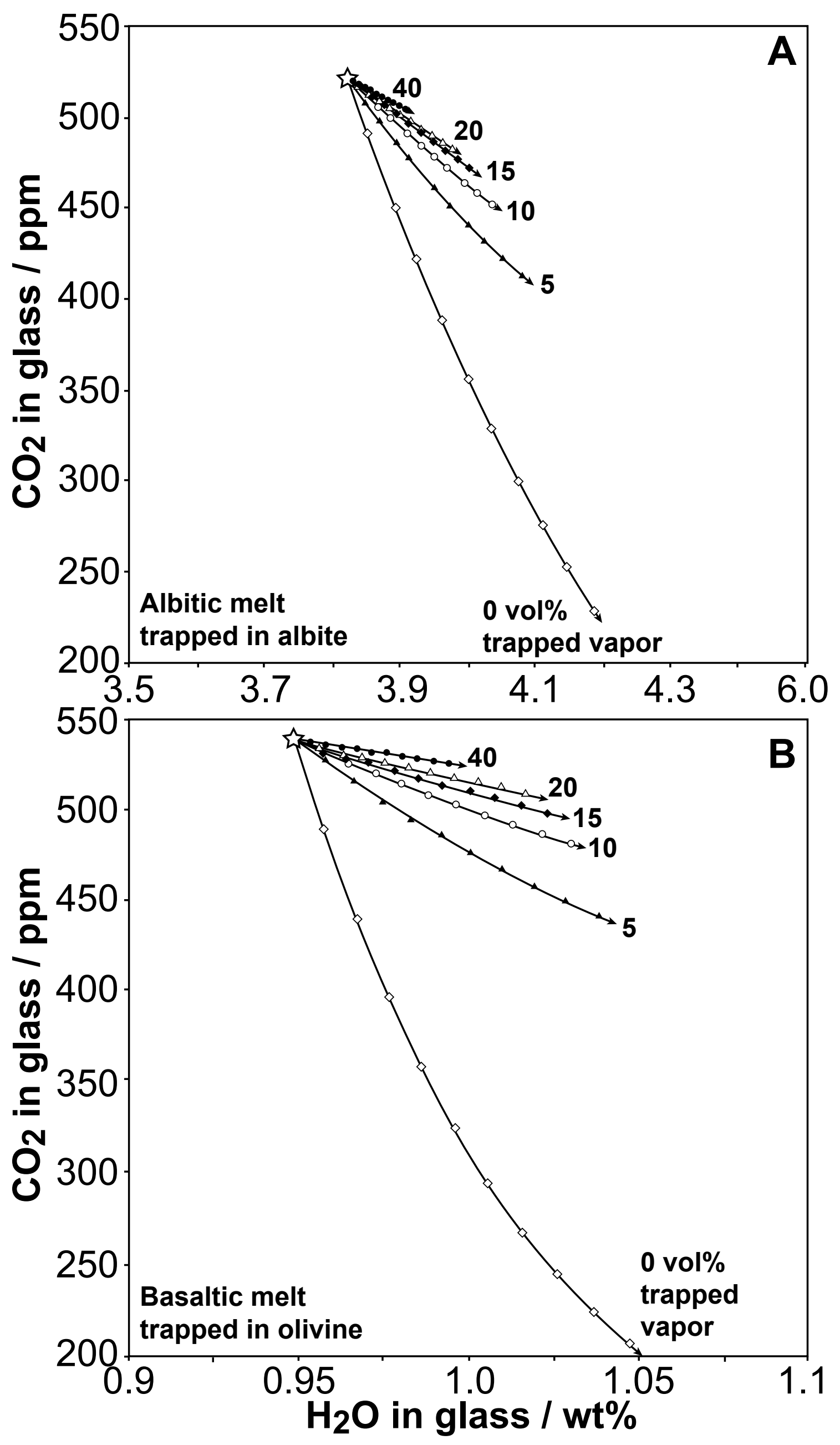









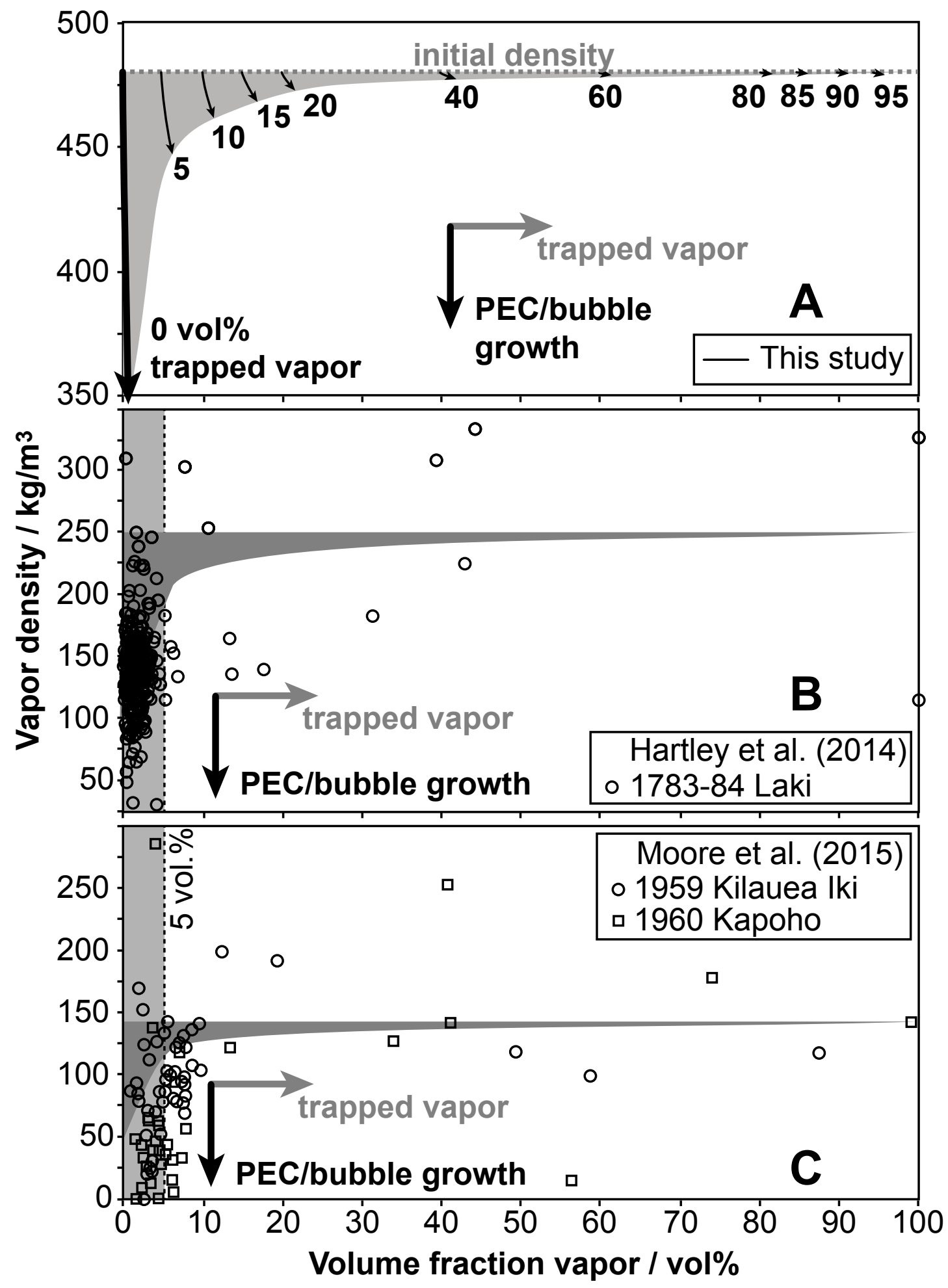

